\title{
Vitamin K-dependent carboxylation
}

\section{Mechanistic studies with 3-fluoroglutamate-containing substrates}

\author{
Anne VIDAL-CROS, Michel GAUDRY* and Andrée MARQUET
}

Laboratoire de Chimie Organique Biologique, C.N.R.S. U.A. 493, Université Paris 6, Tour 44/45 (3ème Étage), 4 Place Jussieu, 75252 Paris CEDEX 05, France

\begin{abstract}
The tripeptides t-butyloxycarbonyl-Xaa-Glu-[$\left.{ }^{3} \mathrm{H}\right]$ Val, where $\mathrm{Xaa}$ is either $(2 R, 3 S)$ - or $(2 R, 3 R)-3$ fluoroglutamate (respectively the erythro and the threo isomer), were synthesized and their behaviour during vitamin K-dependent carboxylation was studied. Neither peptide was carboxylated. The erythro compound gave rise to an HF-elimination product representing $1 \%$ of the starting material. This HF elimination did not occur during incubation of the threo compound. The formation of the dehydropeptide, probably by elimination of an $\mathrm{F}^{-}$anion from an intermediate carbanion, favours the ionic pathway for vitamin $\mathrm{K}$ dependent carboxylation.
\end{abstract}

\section{INTRODUCTION}

The vitamin K-dependent carboxylation of glutamate residues (Suttie, 1984) is a two-step reaction: the C-4-H4 bond is cleaved first and the intermediate thus generated reacts with a $\mathrm{CO}_{2}$ moiety, leading to 4-carboxyglutamate.

The hydrogen-exchange studies by McTigue \& Suttie (1983), Anton \& Friedman (1983) and Ducrocq et al. (1986) established (i) that the reaction is not concerted (the hydrogen exchange occurs in the absence of carboxylation), (ii) that the hydrogen exchange is vitamin $\mathrm{K}$ dependent, (iii) that the hydrogen exchange is faster than the $\mathrm{CO}_{2}$ fixation and (iv) that the stereospecificity of the hydrogen exchange is the same as the stereospecificity observed during carboxylation.

So far, two mechanisms have been considered for the hydrogen-abstraction step: either a radical-mediated mechanism (pathway a) or a carbanion-mediated mech- anism (pathway b) (Scheme 1). The exchange experiments, although they do not strictly rule out the formation of a radical, were interpreted as favouring the carbanion-mediated mechanism. On the other hand, the hypothesis of a radical intermediate is supported by early work by Girardot et al. (1976), who described the inhibition of the carboxylation by spin-trapping reagents. However, no adduct has been unambiguously characterized by e.s.r.

We decided to test the carbanion hypothesis by using a $\beta$-elimination strategy similar to that developed by Abeles and Stubbe, who investigated the non-concerted nature of propionyl-CoA carboxylase mechanism by using $\beta$-fluoropropionyl-CoA (Stubbe \& Abeles, 1977; Stubbe et al., 1980). During carboxylation, formation of a carbanion $\beta$ to the fluorine atom could induce a $\beta$ elimination and yield a dehydroglutamyl moiety (Scheme 2). Alternatively, as suggested by our study on model

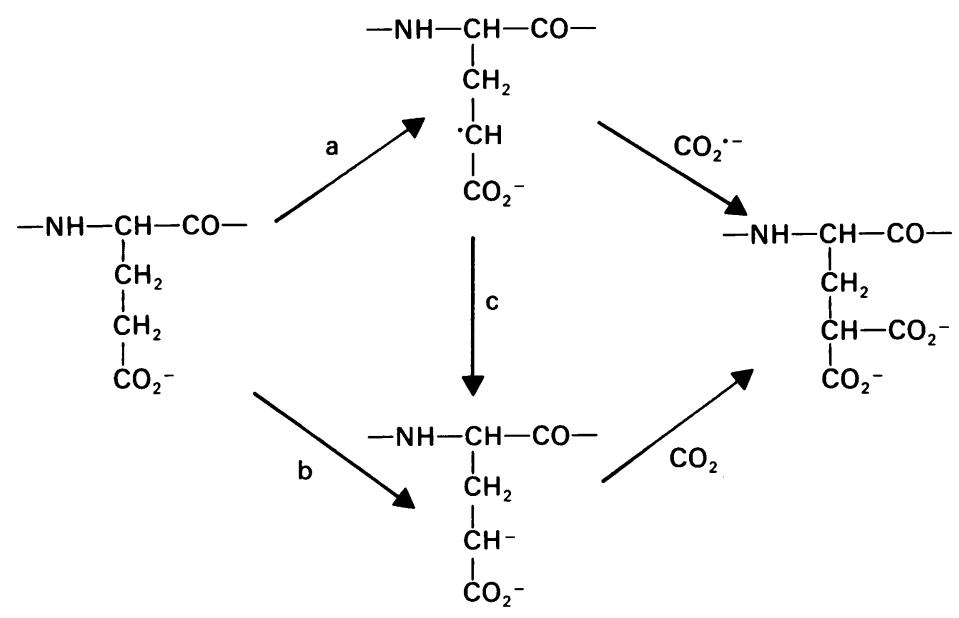

Scheme 1. Ion-mediated and radical-mediated pathways for vitamin K-dependent carboxylation

Abbreviations used: Boc, t-butyloxycarbonyl; Glu $\left(\Delta^{2,3}\right)$ and $\mathrm{Glu}\left(\Delta^{3,4}\right)$ (in peptide sequences), 2,3-dehydroglutamic acid and 3,4-dehydroglutamic acid respectively; $\mathrm{Glu}(3 \mathrm{~F})$ (in peptide sequences), 3-fluoroglutamic acid [Glu(3,F) and $\mathrm{Glu}(3, \mathrm{~F})$ represent the erythro and threo isomers respectively]; Gla (in peptide sequences), 4-carboxyglutamic acid.

* To whom correspondence should be addressed. 


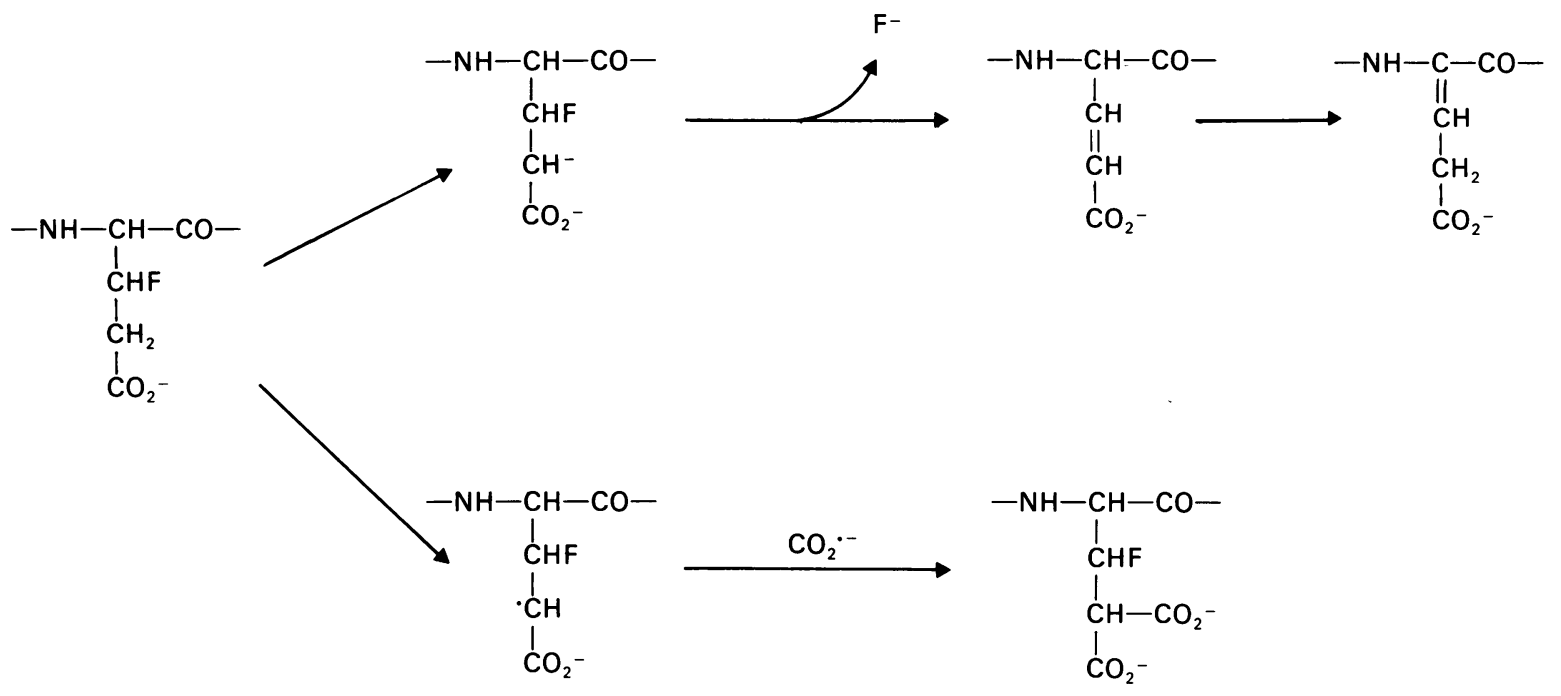

Scheme 2. Expected behaviour of a 3-fluoroglutamate-containing substrate in the carbanion hypothesis and in the radical hypothesis

fluorine-containing radicals, a radical-mediated mechanism would yield the carboxylation product rather than the elimination of a fluorine radical (Vidal-Cros et al., $1989 a$ ).

In the present paper we report the synthesis of BocXaa-Glu-Val tripeptides, where Xaa is a 3-substituted glutamic acid, and their behaviour upon interaction with the vitamin K-dependent carboxylating system.

\section{EXPERIMENTAL}

\section{Chemicals}

Hydroxybenzotriazole, dicyclohexylcarbodi-imide and $N$-hydroxysuccinimide were from Fluka Co. Di-t-butyl pyrocarbonate, NADH, NAD ${ }^{+}$, pyridoxal $5^{\prime}$-phosphate, dithiothreitol, Triton X-100, sucrose, leucine aminopeptidase and acylase I were from Sigma Chemical Co., and all amino acids and derivatives were from Bachem.

All other chemicals were of the highest purity available.

The $(2 R, 3 R)$ - (threo)- and $(2 R, 3 S)$ - (erythro)-3-fluoroglutamic acids were synthesized as described by VidalCros et al. (1989b), who separated the diastereoisomers chromatographically, after preparing them by reductive amination of racemic 3-fluoro-2-oxoglutarate with glutamate dehydrogenase, thus ensuring the $R$-configuration at C-2. The fluoro-oxoglutarate was made by treating ethyl fluoroacetate with diethyl oxalate to obtain diethyl fluoro-oxaloacetate, and then with ethyl bromoacetate, before decarboxylating and de-esterifying with mild acid treatment.

$\mathrm{L}-\left[{ }^{3} \mathrm{H}\right]$ Valine $\quad(25 \mathrm{mCi} / \mathrm{mmol})$ and $\mathrm{NaH}^{14} \mathrm{CO}_{3}$ $(56 \mathrm{mCi} / \mathrm{mmol})$ were from Centre d'Études Atomiques (Saclay, France). The latter was purified before use (Guchhait et al., 1974).

N.m.r.

N.m.r. spectra were recorded on a Brucker WM 250 instrument.

\section{Peptide synthesis}

Boc-L-threo-3-fluoroglutamyl-L-glutamyl-L-valine,
Boc-L-erythro-3-fluoroglutamyl-L-glutamyl-L-valine, Boc-L-glutamyl-L-glutamyl-L-valine, Boc-D-glutamylL-glutamyl-L-valine, Boc-L-threo-3-hydroxyglutamylL-glutamyl-L-valine and Boc-L-erythro-3-hydroxyglutamyl-L-glutamyl-L-valine were synthesized by the liquid-phase methodology with t-butyloxycarbonyl group for amino-group protection and benzyl ester for carboxy-group protection. Coupling was performed through the $N$-hydroxysuccinimic ester. After purification by column chromatography on silica gel, the protected tripeptides were hydrogenolysed with $10 \% \mathrm{Pd}$ on charcoal.

Since 3-fluoroglutamic acid is degraded during hydrolysis with $1 \mathrm{M}-\mathrm{HCl}$ (Vidal-Cros et al., 1985a), no amino acid analysis could be performed. The purity of peptides was checked by h.p.l.c. and $200 \mathrm{MHz}{ }^{1}$ H-n.m.r. spectroscopy.

Boc-L-threo-3-fluoroglutamyl-L-glutamyl-L- $\left[{ }^{3} \mathrm{H}\right]$ valine and Boc-L-erythro-3-fluoroglutamyl-L-glutamyl-L- $\left[{ }^{3} \mathrm{H}\right]-$ valine were prepared analogously starting from L$\left[{ }^{3} \mathrm{H}\right]$ valine. Radiochemical purity of the two peptides was checked by h.p.l.c. Each peptide was contaminated by less than $0.2 \%$ of Boc-Glu( $\left.\Delta^{2,3}\right)-G l u-V a l$, arising from spontaneous HF elimination.

$\operatorname{Boc}-\mathrm{Glu}\left(\Delta^{3,4}\right)$-Glu-Val was obtained by incorporating a 4-phenylselenoglutamate residue protected as the Boc $\gamma$-methyl ester (Bory et al., 1986) into a tripeptide followed by saponification with $1 \mathrm{M}-\mathrm{KOH}$ [4 equivalents; in $50 \%(\mathrm{v} / \mathrm{v})$ ethanol], $\mathrm{H}_{2} \mathrm{O}_{2}$ oxidation and elimination (8.8 equivalents of $\mathrm{H}_{2} \mathrm{O}_{2}$, in tetrahydrofuran at $0^{\circ} \mathrm{C}$ ). ${ }^{1} \mathrm{H}$ n.m.r. $\left(\left[{ }^{2} \mathrm{H}\right]\right.$ chloroform $)$ : the ethylenic protons appear as the $\mathrm{AB}$ part of an $\mathrm{ABX}$ system at $\delta_{\mathrm{A}} 6.09$ p.p.m. and $\delta_{\mathrm{B}}$ 6.95 p.p.m. $\left(2 \mathrm{H}, J_{\mathrm{AB}}=15.8 \mathrm{~Hz}, J_{\mathrm{BX}}=5.7 \mathrm{~Hz}, J_{\mathrm{Ax}}<1 \mathrm{~Hz}\right)$.

$\operatorname{Boc}-\mathrm{Glu}\left(\Delta^{2,3}\right)$-Glu-Val was obtained by isomerization of the 3,4-dehydropeptide in pyridine/methanol or by $\mathrm{HF}$ elimination on the fluorinated peptides by $\mathrm{NaOH}$ at $40{ }^{\circ}$ C. N.m.r. ([$\left.{ }^{2} \mathrm{H}\right]$ chloroform): $\delta$ (p.p.m.) $0.97(3 \mathrm{H}$, doublet, $J=7 \mathrm{~Hz}$ ), 0.98 (3H, doublet, $J=7 \mathrm{~Hz}), 1.45$ (9H, singlet), 1.98 (2H, multiplet), 2.18 (1H, multiplet), 2.43 (2H, multiplet), $3.18(2 \mathrm{H}$, doublet, $J=7 \mathrm{~Hz}), 4.25$ (1H, multiplet), 4.55 (1H, multiplet), 6.28 (1H, triplet, $J=7 \mathrm{~Hz}), 8.15$ (2H, multiplet) and 8.37 (1H, multiplet). 


\section{Standard assay of carboxylase}

Liver microsomal fractions were prepared from warfarin-treated rats $(13.4 \mathrm{~mm}, 10 \mathrm{mg} / \mathrm{kg})$ as previously described (Rikong-Adie et al., 1980; Decottignies-Le Maréchal et al., 1980). The incubation mixture (final $\mathrm{pH} 7.58$ ) contained $50 \mathrm{~mm}-\mathrm{KH}_{2} \mathrm{PO}_{4}, 0.6 \mathrm{M}-\mathrm{KCl}, 0.25 \mathrm{M}-$ sucrose, $1.33 \mathrm{~mm}$-pyridoxal $5^{\prime}$-phosphate, $2.22 \mathrm{~mm}$ NADH, $3.9 \mu \mathrm{M}-\mathrm{NAD}^{+}, 0.39 \mathrm{~mm}$-dithiothreitol, $0.22 \mathrm{~mm}$ vitamin $\mathrm{K}_{1}$ hydroquinone, $1.5 \%(\mathrm{v} / \mathrm{v})$ Triton $\mathrm{X}-100$, 7-9 mg of microsomal protein $/ \mathrm{ml}$ and 1-3 mM-peptide. After preincubation $\left(5 \mathrm{~min}\right.$ at $20^{\circ} \mathrm{C}$ ), the reaction was initiated by addition of $\mathrm{NaH}^{14} \mathrm{CO}_{3}(0.32 \mathrm{~mm})$ and stopped after $30 \mathrm{~min}$ by addition of trichloroacetic acid [10\% (w/v) final concentration]. After centrifugation, a sample of the supernatant was evaporated to dryness and radioactivity was measured in an Intertechnique SL 30 scintillation counter in Aquasol-2. Blank experiments without vitamin $\mathrm{K}$ or without substrate were run in the same conditions.

Protein was determined by the method of Lowry et al. (1951), with BSA as standard.

\section{Isomerization of Boc-Glu( $\left.\Delta^{3,4}\right)-G l u-V a l$ into Boc- Glu( $\left.\Delta^{2,3}\right)$-Glu-Val}

$\operatorname{Boc}-\mathrm{Glu}\left(\Delta^{3,4}\right)$-Glu-Val $(1 \mathrm{~mm})$ was incubated at $22^{\circ} \mathrm{C}$ in the incubation mixture described above but containing heat-denatured microsomal fraction and non-labelled $\mathrm{NaHCO}_{3}$. The reaction was monitored over a $5 \mathrm{~h}$ period on samples previously precipitated with ethanol $(50 \%$, $\mathrm{v} / \mathrm{v}$ ), and centrifuged. H.p.l.c. analysis was performed on a $\mu$ Bondapak $\mathrm{C}_{18}$ column, eluted with $0.25 \mathrm{~mm}$ triethylammonium phosphate, $\mathrm{pH} \mathrm{3}$, containing $22 \%$ $(\mathrm{v} / \mathrm{v})$ acetonitrile at a rate of $1 \mathrm{ml} / \mathrm{min}$ and monitored at $210 \mathrm{~nm}$.

\section{Incubation of the Boc-Glu(3F)-Glu- $\left[{ }^{3} \mathbf{H}\right]$ Val tripeptides}

The assay was run on Boc-Glu(3F)-Glu- $\left[{ }^{3} \mathrm{H}\right] \mathrm{Val}$ ( $3 \mathrm{~mm} ; 0.28 \mathrm{mCi} / \mathrm{mmol}$ ) in a $2 \mathrm{ml}$ total volume in the standard conditions, except that non-radioactive $\mathrm{NaHCO}_{3}(0.32 \mathrm{~mm})$ was included. After incubation at $20^{\circ} \mathrm{C}$ for $2 \mathrm{~h}$, proteins were precipitated by ethanol $(2 \mathrm{ml})$ and centrifuged at $1000 \mathrm{~g}$ for $15 \mathrm{~min}$. The whole supernatant was then incubated at $20^{\circ} \mathrm{C}$ for $3 \mathrm{~h}$ and concentrated to dryness. A sample of the crude mixture was analysed by h.p.l.c. on a Merck Lichrospher 100 RP$8 \mathrm{e}(5 \mu \mathrm{m}$ particle size) column eluted at $1 \mathrm{ml} / \mathrm{min}$ with $0.25 \mathrm{M}$-triethylammonium phosphate, $\mathrm{pH} \mathrm{3}$, containing $18 \%(\mathrm{v} / \mathrm{v})$ acetonitrile. Fractions $(1 \mathrm{ml})$ were collected and radioactivity was determined. A blank experiment where vitamin $K$ was omitted was run in the same conditions.

\section{Purification of the product derived from incubation of erythro-Boc-Glu(3F)-Glu- $\left[{ }^{3} \mathrm{H}\right] \mathrm{Val}$}

The crude product was purified by h.p.l.c. on a Merck Lichrosorb RP-18 (1 $\mu \mathrm{m}$ particle size) column eluted at $3 \mathrm{ml} / \mathrm{min}$ with $0.25 \mathrm{~mm}$-triethylammonium phosphate, pH 3, containing $18 \%(\mathrm{v} / \mathrm{v})$ acetonitrile. Fractions $(3 \mathrm{ml})$ were collected. The dehydropeptide-like fractions, detected by u.v. light at $210 \mathrm{~nm}$, were pooled, concentrated under reduced pressure and freeze-dried. The salts were removed by purification of the recovered material on a $\mathrm{C}_{18}$ Sep-Pak cartridge. After being washed with $70 \mathrm{ml}$ of water, the product was eluted with $3 \mathrm{ml}$ of methanol. The radiochemical purity of the product was checked again by h.p.l.c.

\section{Identification of the product derived from incubation of erythro-Boc-Glu(3F)-Glu- $\left[^{3} \mathrm{H}\right] \mathrm{Val}$}

The above purified product, diluted with non-labelled Boc-Glu $\left(\Delta^{2,3}\right)$-Glu-Val $(0.4 \mu \mathrm{mol})$, was hydrogenated with $10 \% \mathrm{Pd}$ on charcoal in $0.75 \mathrm{ml}$ of methanol. After vigorous stirring for $3 \mathrm{~h}$, the catalyst was filtered off and washed with methanol, and the product was analysed by h.p.l.c. on a Merck Lichrospher 100 RP-8e (5 $\mu \mathrm{m}$ particle size) column eluted at $1 \mathrm{ml} / \mathrm{min}$ with $0.25 \mathrm{M}$ triethylammonium phosphate, $\mathrm{pH} \mathrm{3}$, containing $12.8 \%$ (v/v) acetonitrile. Fractions (either $1 \mathrm{ml}$ or $0.2 \mathrm{ml}$ ) were collected and radioactivity was determined on $0.2 \mathrm{ml}$ samples.

\section{Tritium release assay}

Buffers and solutions were prepared with freshly boiled water in order to lower the bicarbonate concentration down to $0.5-1 \mathrm{~mm}$. An incubation was run on $6.75 \mu \mathrm{Ci}$ of Boc- $(2 S)-\left[2,3-{ }^{3} \mathrm{H}\right] \mathrm{Glu}-\mathrm{Glu}-\mathrm{Val}$ (1 mM; specific radioactivity $13.5 \mathrm{mCi} / \mathrm{mmol}$ ) as described for a standard assay. After incubation at $20^{\circ} \mathrm{C}$ for $5 \mathrm{~h}$, the proteins were precipitated by addition of trichloroacetic acid $[10 \%(w / v)$ final concentration] and centrifuged. The supernatants were freeze-dried and radioactivity was determined on both the recovered water and the freezedried material (water, 6172 d.p.m.; freeze-dried material, $42.46 \times 10^{6}$ d.p.m.). A blank experiment without vitamin $\mathrm{K}$ was run in the same conditions (water, 1959 d.p.m.; freeze-dried material, $32.52 \times 10^{6}$ d.p.m.). This corresponded to an exchange of $0.0085 \%$.

\section{RESULTS}

\section{Carboxylation of fluoropeptides}

Since the carboxylation of Phe-Leu-Glu-Glu-Val or Boc-Glu-Glu-Val occurs almost exclusively at the first glutamate residue (Decottignies-Le Maréchal et al., 1980), the 3-substituted glutamates were introduced at that position. To facilitate the detection and the purification of the products formed upon reaction of the fluorinated substrates, radioactive peptides labelled with $\left[{ }^{3} \mathrm{H}\right]$ valine were prepared. The tripeptides were synthesized by the liquid-phase method, with t-butyloxycarbonyl group for amino-group protection and benzyl ester for carboxy-group protection, and tested for carboxylation. Results are given in Table 1.

As already observed, the tripeptide Boc-Glu-Glu-Val, although being one of the best of the synthetic peptides commonly used to study vitamin $\mathrm{K}$-dependent carboxylation (Rich et al., 1980), remained a poor substrate for the enzyme $(0.1 \%$ reaction at a peptide concentration of $1 \mathrm{~mm}$ with $30 \mathrm{~min}$ incubation time). However, the ${ }^{14} \mathrm{CO}_{2}$ incorporations with this substrate were significant with respect to the very low value of the blanks (see Table 1). On the other hand the ${ }^{14} \mathrm{CO}_{2}$ incorporation into both fluorinated peptides was not significantly different from the blank and they could not thus be considered as being substrates of the carboxylase.

The lack of carboxylation of the fluorinated peptides prompted us to look for an HF-elimination product. Previous studies in this laboratory had shown that Boc$\operatorname{Glu}\left(\Delta^{3,4}\right)$-OMe isomerized to Boc-Glu( $\left.\Delta^{2,3}\right)$-OMe (Bory 
Table 1. Vitamin K-dependent carboxylation of 3-fluoroglutamate-containing peptides Boc-Xaa-Glu-Val

After preincubation at $20^{\circ} \mathrm{C}$ for $5 \mathrm{~min}$, the reaction (final volume $0.225 \mathrm{ml}$ ) was initiated by addition of $\mathrm{NaH}^{14} \mathrm{CO}_{3}$. Then $30 \mathrm{~min}$ later the reaction was stopped with trichloroacetic acid, the mixture was centrifuged and the radioactivity was determined on a $0.1 \mathrm{ml}$ sample of the supernatant.

\begin{tabular}{|c|c|c|c|}
\hline Peptide & $\begin{array}{c}\text { Radioactivity } \\
\text { incorporated (d.p.m.)* }\end{array}$ & $\begin{array}{c}\text { Carboxylation } \\
\text { (\% with respect to } \\
\text { Boc-Xaa-Glu-Val) }\end{array}$ & $\mathrm{IC}_{50}{ }^{\dagger}$ \\
\hline Boc-Glu-Glu-Val (1 mM) & 11001 & 0.11 & \\
\hline Boc-Glu $(3, F)-$ Glu-Valf $(3 \mathrm{~mm})$ & 35 & 0.000115 & $3 \mathrm{~mm}$ \\
\hline Boc-Glu $(3, F)-G l u-V a l \ddagger(3 \mathrm{~mm})$ & 57 & 0.000187 & $3 \mathrm{~mm}$ \\
\hline
\end{tabular}

* The blank value without vitamin K (45 d.p.m.) was subtracted.

$\dagger[$ Boc-Glu-Glu-Val] $=1 \mathrm{~mm}$.

$\ddagger$ Fluorinated analogues bear some resemblance to their hydroxylated analogues (Barnett, 1972; Briley et al., 1975). The 3hydroxyglutamic acids were prepared, resolved and incorporated into tripeptides. The threo and erythro isomers (5 mM) were not significantly carboxylated (respectively 56 and 69 d.p.m. incorporation).

et al., 1986) with a half-life of 4 min in the carboxylation conditions (i.e. phosphate buffer, $\mathrm{pH}$ 7.58). Similar h.p.l.c. studies, performed on Boc-Glu $\left(\Delta^{3,4}\right)-$ Glu-Val, the expected elimination product, revealed that this peptide also underwent isomerization into $\operatorname{Boc}-\operatorname{Glu}\left(\Delta^{2,3}\right)$ Glu-Val. Albeit slower than the isomerization of Boc$\operatorname{Glu}\left(\Delta^{3,4}\right)$-OMe, this isomerization was relatively fast $\left(t_{\frac{1}{2}} 73 \mathrm{~min}\right)$ with respect to the incubation time $(2 \mathrm{~h})$. In order to avoid performing the purification and identification procedures on mixtures of 2,3- and 3,4-dehydropeptides, the 3,4-dehydropeptide was allowed to isomerize as thoroughly as possible before treatment. We checked (detection with u.v. light) that the fluoropeptides did not eliminate HF under these isomerization con- ditions. As shown in Fig. 1, incubation of erythro-BocGlu(3F)-Glu- $\left[{ }^{3} \mathrm{H}\right]$ Val followed by isomerization resulted in the formation of a radioactive product that was detectable by u.v. absorption at $210 \mathrm{~nm}$ (elution between 15 and $17 \mathrm{~min}$ ) and co-migrated with standard Boc$\operatorname{Glu}\left(\Delta^{2,3}\right)$-Glu-Val. (The radioactive material that emerged between 18 and 19 min did not absorb at $210 \mathrm{~nm}$, and so was not a peptide.) The enzymic origin of this product was verified by two blanks run either without vitamin $\mathrm{K}$ or with heat-denaturated liver microsomal fraction. In contrast, the threo-3-fluoroglutamate-containing tripeptide did not give rise to this product (Table 2).

This product represented about $1 \%$ of the starting

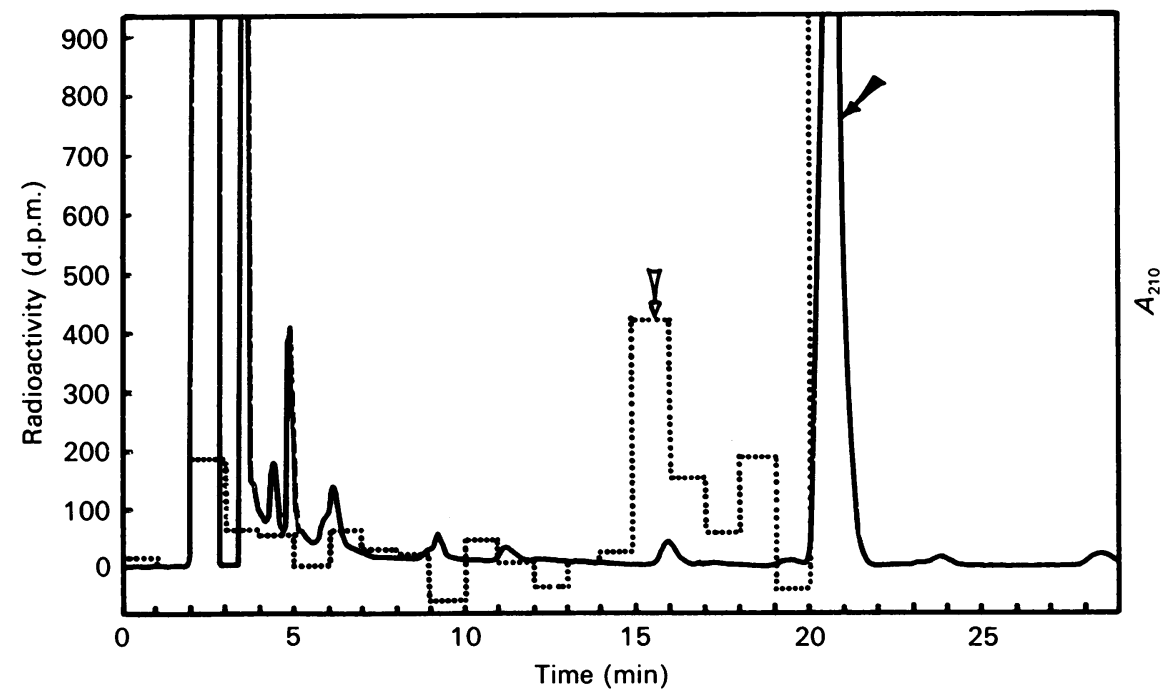

Fig. 1. H.p.l.c. of the erythro-Boc-Glu(3F)-Glu- $\left[{ }^{3} \mathrm{H}\right]$ Val carboxylation product

erythro-Boc-Glu(3F)-Glu- $\left[{ }^{3} \mathrm{H}\right] \mathrm{Val}(3 \mathrm{mM})$ was incubated at $20^{\circ} \mathrm{C}$ for $2 \mathrm{~h}$ in a carboxylation assay containing non-labelled $\mathrm{NaHCO}_{3}(0.3 \mathrm{mM})$. After precipitation of the proteins by ethanol $(50 \%, \mathrm{v} / \mathrm{v})$ and centrifugation, the supernatant was incubated at $20^{\circ} \mathrm{C}$ for $3 \mathrm{~h}$. A blank experiment without vitamin $\mathrm{K}$ hydroquinone was run under the same conditions. Samples of these incubation mixtures were analysed by h.p.l.c. on a Merck Lichrospher 100 RP-8e (5 $\mu$ m particle size) column. Eluting buffer was $0.25 \mathrm{~mm}$-triethylammonium phosphate, $\mathrm{pH} \mathrm{3}$, containing $18 \%(\mathrm{v} / \mathrm{v})$ acetonitrile, at a rate of $1 \mathrm{ml} / \mathrm{min}$. Monitoring of the eluate was at $210 \mathrm{~nm}(-)$. Fractions $(1 \mathrm{ml})$ were collected and the radioactivity was determined $(\cdots \cdots)$. The arrows indicate the retention times of the standard peptides: $\downarrow$, Boc-Glu $\left(\Delta^{2,3}\right)-G l u-V a l ; ~ \mid$, erythro-Boc-Glu(3F)-Glu-Val or Boc-Glu( $\left.\Delta^{3,4}\right)-$ Glu-Val. 
Table 2. Incubation of Boc-Glu(3F)-Glu- $\left.\right|^{3} \mathrm{H} \mid \mathrm{Val}(1.7 \mu \mathrm{Ci})$ : extent of elimination

Analysis of h.p.l.c. profiles was achieved either by measuring the radioactivity of $1 \mathrm{ml}$ collected fractions $(a)$ or by integration of the areas under the peaks detected at $210 \mathrm{~nm}(b)$. The results, expressed as percentages of the ratio of the dehydropeptide formed to the remaining fluorinated peptide, are the averages for three independent determinations.

\begin{tabular}{|c|c|c|c|c|}
\hline \multirow{3}{*}{ Peptide (3 mM) } & \multicolumn{4}{|c|}{ Extent of elimination $(\%)$} \\
\hline & \multicolumn{2}{|c|}{$\begin{array}{l}\text { Vitamin K } \\
\text { omitted }\end{array}$} & \multicolumn{2}{|c|}{$\begin{array}{c}\text { Vitamin } K \\
\text { present }\end{array}$} \\
\hline & (a) & (b) & $(a)$ & (b) \\
\hline $\begin{array}{l}\text { Boc-Glu(3,F)-Glu- }\left[{ }^{3} \mathrm{H}\right] \text { Val } \\
\text { Boc-Glu }(3, F)-G l u-\left[{ }^{3} \mathrm{H}\right] \text { Val }\end{array}$ & $\begin{array}{l}1.00^{*} \\
0.59\end{array}$ & $\begin{array}{l}0.20 \\
0.22\end{array}$ & $\begin{array}{l}1.96 \\
0.58\end{array}$ & $\begin{array}{l}1.00 \\
0.16\end{array}$ \\
\hline
\end{tabular}

* This value probably reflects the presence of an impurity, labelled but not absorbing at $210 \mathrm{~nm}$, that may be the one referred to later in the text.

material, a value that was larger than the carboxylation yield of Boc-Glu-Glu-Val, which is in the $0.3-0.4 \%$ range under those conditions. This was consistent with the conclusion derived from exchange experiments (see above) that the slower step of the reaction is the addition of $\mathrm{CO}_{2}$ to the intermediate.

To reinforce the identification of the product as the dehydropeptide, we ran a hydrogenation catalysed by $\mathbf{P d}$ on charcoal. Preliminary experiments on the dehydropeptide, obtained either by isomerization of synthetic 3,4-dehydropeptide or by HF elimination from the fluoropeptide, indicated that the reaction was fast, clean and led to both Boc-L-Glu-L-Glu-L-Val and Boc-D-GluL-Glu-L-Val with a diastereoisomeric excess of $43 \%$ favouring the latter. The radioactive fractions eluted between 15 and 17 min (elution time of the dehydropeptide) were hydrogenated. Analysis of the product thus obtained revealed two peaks of radioactivity, eluted respectively as Boc-L-Glu-L-Glu-L-Val and Boc-D-Glu-LGlu-L-Val (Fig. 2). The amounts of radioactive materials

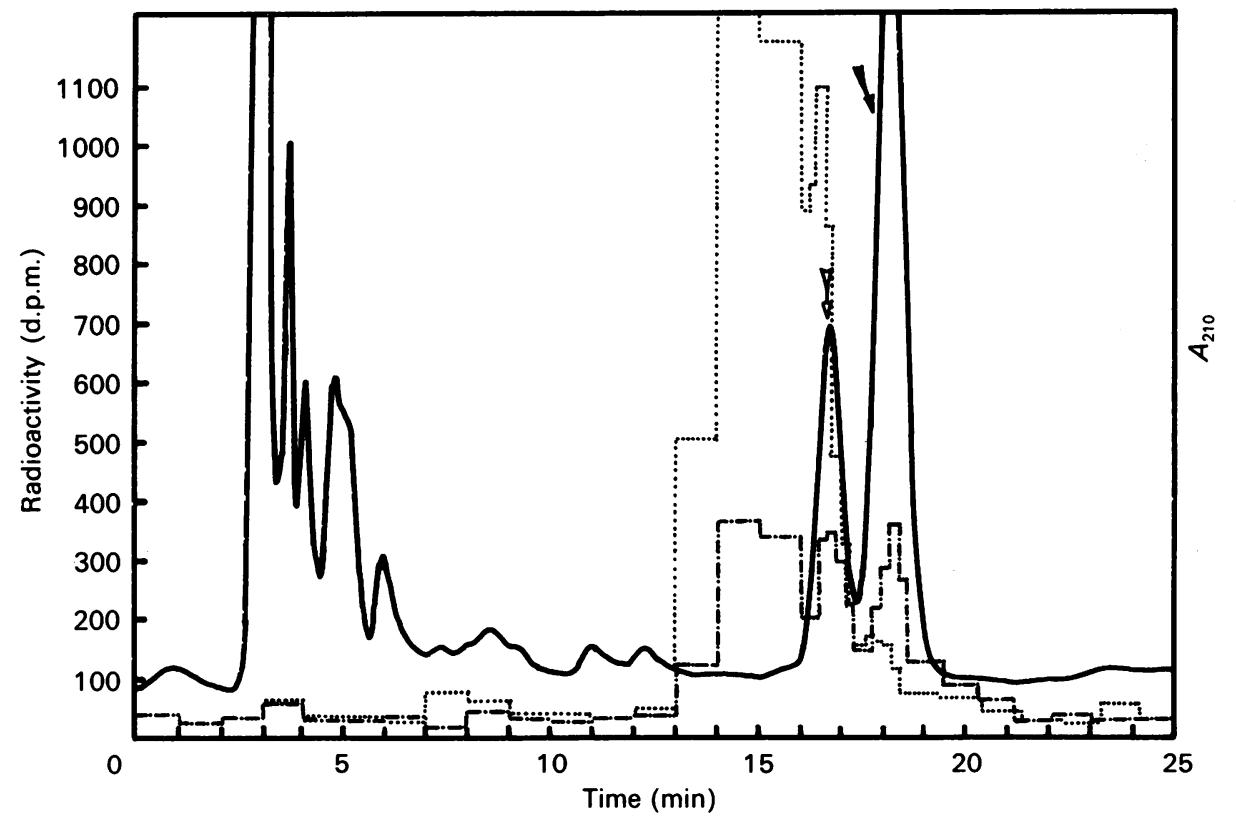

Fig. 2. H.p.l.c. analysis of the hydrogenation product of Boc-Glu( $\left(\Delta^{2,3}\right)-G l u-\left[{ }^{3} \mathrm{H}\right] \mathrm{Val}$ resulting from the carboxylation of erythro-BocGlu(3F)-Glu- $\left[{ }^{3} \mathbf{H}\right]$ Val

The carboxylation product of Boc-Glu(3F)-Glu- $\left[{ }^{3} \mathrm{H}\right]$ Val, purified on a Merck Lichrosorb RP-18 (7 $\mu \mathrm{m}$ particle size) column and on a $\mathrm{C}_{18}$ Sep-Pak cartridge, was diluted with $0.4 \mu \mathrm{mol}$ of synthetic Boc-Glu( $\left.\Delta^{2,3}\right)$-Glu-Val and hydrogenated on Pd on charcoal for $3 \mathrm{~h}$ in methanol. The crude product was analysed by h.p.l.c. on a Merck Lichrospher $100 \mathrm{RP}-8 \mathrm{e}(5 \mu \mathrm{m}$ particle size) column. Eluting buffer was $0.25 \mathrm{~mm}$-triethylammonium phosphate, $\mathrm{pH} \mathrm{3}$, containing $12.8 \%(\mathrm{v} / \mathrm{v})$ acetonitrile, at a rate of $1 \mathrm{ml} / \mathrm{min}$. Monitoring of the eluate was at $210 \mathrm{~nm}$ (-). Fractions $(1 \mathrm{ml}$ or $0.2 \mathrm{ml})$ were collected and the radioactivity was determined $(\cdots$, , blank; -.-.-., assay). The arrows indicate the retention times of the standard peptides: $\downarrow$, Boc-L-Glu-L-Glu-L-Val; $\downarrow$, Boc-D-Glu-L-Glu-L-Val. 
were almost identical in both peaks, whereas the u.v. monitoring indicated an excess of the DLL-isomer over the LLL-isomer, as observed previously. This suggested that the peak corresponding to the LLL-isomer was contaminated by a radioactive impurity. A peak eluted at the retention time of the DLL-isomer was present in the blank in even higher amount than in the assay (presumably because the fractions containing eventually the dehydro compound were collected blindly to avoid loss of product) whereas nothing was eluted at the retention time of the DLL-isomer. This established (i) that no dehydropeptide was formed in the blank, and (ii) that, even though no unambiguous conclusion can be drawn from the peak eluted at the retention time of the LLL-isomer, the existence of a radioactive peak at the retention time of the DLL-isomer in the assay proves that dehydropeptide was present after incubation with the carboxylase.

\section{DISCUSSION}

\section{Mechanism of dehydropeptide formation}

Two elementary mechanisms could account for the formation of a dehydropeptide from the erythro-3fluoroglutamate-containing tripeptide: $\mathrm{F}^{\cdot}$ elimination on a radical intermediate (eqn. 1) or $\mathrm{F}^{-}$elimination on a carbanion intermediate (eqn. 2):

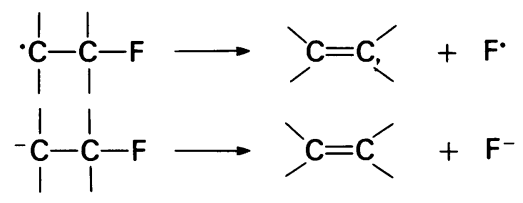

The energy required for the homolytic breaking of the C-F bond is very high (Patai, 1973). Previous studies of $\alpha$-fluoro-containing radicals suggested that the first possibility (eqn. 1) was very unlikely (Barton et al., 1966; Herdewijn et al., 1987). We also checked (VidalCros et al., 1989a) that no elimination was occurring during the homolytic decarboxylation of the 3-fluoroglutamates according to Barton et al. (1983). Thus the fastest reaction undergone by an $\alpha$-fluoro radical is the trapping of an $\mathrm{H}^{*}$ radical rather than $\mathrm{F}^{*}$ radical elimination or dimerization. If a radical intermediate were involved in the carboxylation, it would probably exhibit the same reactivity and react with another radical $\left(\mathrm{H}^{\cdot}\right.$ or $\left.\mathrm{CO}_{2}{ }^{-}\right)$rather than eliminate the $\mathrm{F}^{\cdot}$ radical. $\mathrm{F}^{-}$ anion elimination from a carbanion intermediate (eqn. 2), already used in many studies such as mechanismbased enzyme inhibition (Walsh, 1982; Rando, 1984), seemed to be the most attractive of those simple mechanisms that could account for the dehydropeptide formation. [Stubbe and colleagues (Harris et al., 1987) suggested the existence of a radical cation and the $\mathrm{HF}$ elimination to account for the inactivation of ribonucleotide reductase by 2 '-deoxy-2'-fluororibonucleotide. However, in this case the radical cation was stabilized by an adjacent donor hydroxy group.]

The dehydropeptide could also be formed by the decarboxylation of Boc-Gla(3F)-Glu-Val (Scheme 3). The fact that no ${ }^{14} \mathrm{CO}_{2}$ was incorporated in the carboxylation assay excluded, a priori, a non-stereospecific decarboxylation $\left({ }^{14} \mathrm{CO}_{2}\right.$ would have been present in the dehydropeptide). It would have required an efficient (concerted?) decarboxylation-fluoride elimination at the active site. This would have implied that the extent of carboxylation of Boc-Glu( $\left.3_{e} \mathrm{~F}\right)$-Glu-Val $(1 \%$ in that hypothesis) exceeded that of Boc-Glu-Glu-Val $(0.3-0.4 \%)$. This makes that possibility very unlikely, since the $\mathrm{CO}_{2}$ incorporation is the slow step of the overall reaction (Ducrocq et al., 1986). (Furthermore, malonic protons being very acidic and the presence of fluorine reinforcing this acidity, proton abstraction should be favoured over decarboxylation and should yield a ${ }^{14} \mathrm{C}$ labelled product in the carboxylation experiments.) The 2,3-dehydropeptide could have been produced directly by elimination on a carbanion non-specifically generated at the 2-position. However, the stability of the fluorinated peptide under the incubation conditions and the strict dependence of the elimination on the presence of vitamin $\mathrm{K}$ make this possibility improbable also. (We checked that no exchange of the 2-hydrogen of Boc-L- $\left[2,3-{ }^{3} \mathrm{H}\right] \mathrm{Glu}-$ Glu-Val with solvent could be detected during the carboxylation. If the same situation holds for the fluorinated peptide, this makes the formation of the 2,3dehydropeptide by abstraction of the 2-hydrogen very unlikely.)

Provided that the presence of fluorine does not induce a driving force sufficient to modify the reaction pathway when going from Boc-Glu-Glu-Val to Boc-Glu(3F)-Glu-

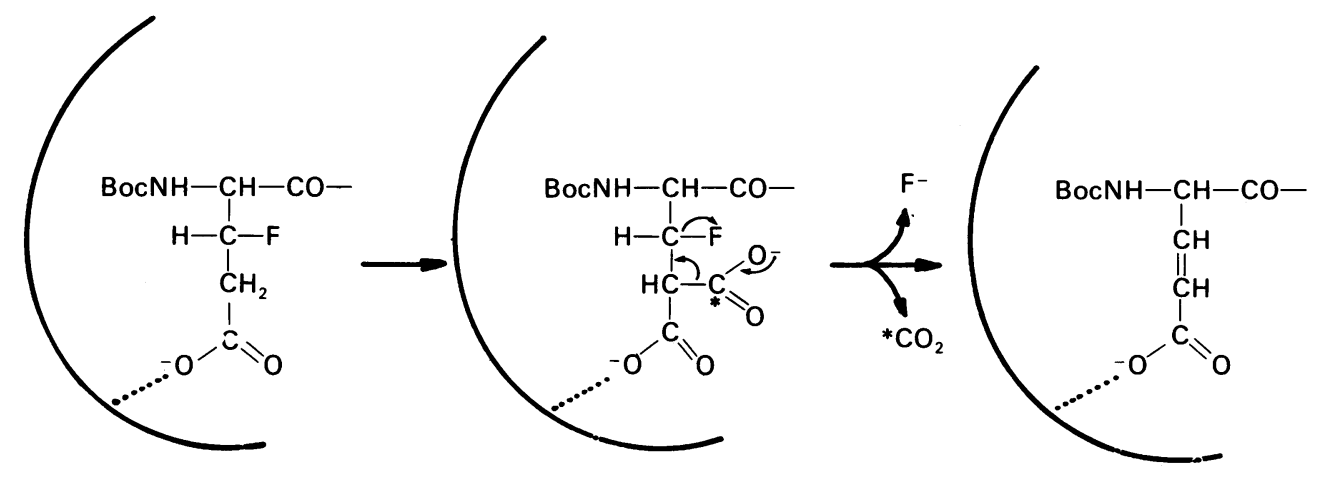

Scheme 3. Putative formation of dehydropeptide by carboxylation-decarboxylation

This possibility is very improbable (see the text). 
Val, our result supports the involvement of a carbanionic intermediate during the enzymic carboxylation.

The difference between the Boc-Glu(3,F)-Glu-Val, which yielded a dehydropeptide, and Boc-Glu(3,F)-GluVal, which did not eliminate, can be interpreted on the basis of the stereochemical features necessary for the elimination reaction, i.e. the relative orientations of F-3 and $\mathrm{H}-4$ are not fulfilled by the threo isomer whereas the proper conformation is achieved with the erythro isomer. We have already observed such a reactivity difference between the threo-and erythro-3-fluoroglutamate isomers during reaction with glutamate decarboxylase (VidalCros et al., 1985b): the threo isomer simply decarboxylates whereas the erythro isomer decarboxylates and eliminates an $\mathrm{F}^{-}$anion.

\section{CONCLUSION}

The erythro-Boc-Glu(3F)-Glu-Val yielded an $\mathrm{HF}$ elimination product upon carboxylation. The most attractive mechanism that can rationalize this result is an $\mathrm{F}^{-}$. elimination on a carbanion intermediate (Scheme 1, pathway b).

However, the present study does not rule out a radicalmediated mechanism yielding first a radical species that would be reduced into a carbanion in a second step (Scheme 1, pathway c). This pathway has to be tested.

Bernard Rousseau and his co-workers (C.E.A., Saclay, France) are gratefully acknowledged for tritiation experiments.

\section{REFERENCES}

Anton, D. L. \& Friedman, P. A. (1983) J. Biol. Chem. 258, 14084-14087

Barnett, J. E. G. (1972) Ciba Found. Symp. 95-110

Barton, D. H. R., Basu, N. K., Hesse, R. H., Morehouse, F. S. \& Pechet, M. M. (1966) J. Am. Chem. Soc. 88, 3016-3021

Barton, D. H. R., Crich, D. \& Motherwell, W. B. (1983) J. Chem. Soc. Chem. Commun. 939-941

Bory, S., Gaudry, M. \& Marquet, A. (1986) Nouv. J. Chim. 10, 709-713

Received 31 July 1989/4 October 1989; accepted 11 October 1989
Briley, P. A., Eisenthal, R. \& Harrison, R. (1975) Biochem. J. 145, 501-507

Decottignies-Le Maréchal, P., Rikong-Adie, H., Azerad, R. \& Gaudry, M. (1980) Biochem. Biophys. Res. Commun. 90, 700-707

Ducrocq, C., Righini-Tapie, A., Azerad, R., Green, J. F., Friedman, P. A., Beaucourt, J. P. \& Rousseau, B. (1986) J. Chem. Soc. Perkin Trans 1 1323-1328

Girardot, J. M., Mack, D. O., Floyd, R. A. \& Johnson, B. C. (1976) Biochem. Biophys. Res. Commun. 70, 655-662

Guchhait, R. B., Polakis, S. E., Dimroth, P., Stoll, E., Moss, J. \& Lane, M. D. (1974) J. Biol. Chem. 249, 6633-6645

Harris, G., Ashley, G. W., Robins, M. J., Tolman, R. L. \& Stubbe, J. (1987) Biochemistry 26, 1895-1902

Herdewijn, P., Pauwels, R., Baba, M., Balzarini, J. \& De Clerq, E. (1987) J. Med. Chem. 30, 2131-2137

Lowry, O. H., Rosebrough, N. J., Farr, A. L. \& Randall, R. J. (1951) J. Biol. Chem. 193, 265-275

McTigue, J. J. \& Suttie, J. W. (1983) J. Biol. Chem. 258, 12129-12131

Patai, S. (1973) The Chemistry of the Carbon-Halogen Bond, part 1, pp. 1-43, John Wiley and Sons, New York

Rando, R. (1984) Pharmacol. Rev. 36, 111-142

Rich, D. H., Lerhman, S. R., Kawai, M., Goodman, H. L. \& Suttie, J. W. (1980) in Vitamin K Metabolism and Vitamin K-Dependent Proteins (Suttie, J. W., ed.), pp. 471-479, University Park Press, Baltimore

Rikong-Adie, H., Decottignies-Le Maréchal, P., Azerad, R. \& Marquet, A. (1980) in Vitamin K Metabolism and Vitamin K-Dependent Proteins (Suttie, J. W., ed.), pp. 518-526, University Park Press, Baltimore

Stubbe, J. \& Abeles, R. H. (1977) J. Biol. Chem. 252, 8338-8340

Stubbe, J., Fish, S. \& Abeles, R. H. (1980) J. Biol. Chem. 255, 236-242

Suttie, J. W. (1984) Handbook of Vitamins: Nutritional, Biochemical and Clinical Aspects (Machlin, L. J., ed.), pp. 147-198, Marcel Dekker, New York

Vidal-Cros, A., Gaudry, M. \& Marquet A. (1985a) J. Org. Chem. 50, 3163-3167

Vidal-Cros, A., Gaudry, M. \& Marquet, A. (1985b) Biochem. J. 229, 675-678

Vidal-Cros, A., Bory, S., Gaudry, M. \& Marquet, A. (1989a) Tetrahedron Lett. 30, 1799-1802

Vidal-Cros, A., Gaudry, M. \& Marquet, A. (1989b) J. Org. Chem. 54, 498-500

Walsh, C. (1982) Tetrahedron 38, 871-909 